\section{Superior-Mirage Photographs: Evidence of Complex Air Temperature Profiles in Sonoran Desert Valleys}

\author{
Allan D. Matthias and Nancy Ferguson, Department \\ of Soil and Water Science, University of Arizona, \\ Tucson, $A Z 85721$
}

Sightings of superior and inferior mirages have long been reported in various areas of the western North American deserts (Ives, 1948). In the Sonoran Desert atmospheric conditions are often favorable for mirage formation. Meinel and Meinel (1983), for example, observed spectacular mirages formed by light refraction within cool stratified air in Sonoran Desert valleys at dawn near Tucson, Arizona. Recently, we both began to observe and photograph the sometimes subtle but fascinating mirage phenomena that occur in the lower atmopshere of the Sonoran Desert. In this correspondence we present a brief description of mirage phenomena and selected photographs of superior-mirage images that we have observed in some desert valleys of southern Arizona. We also present a brief characterization of the meteorological conditions associated with some of the observed mirage images.

Discussions of the current understanding of mirage phenomena are given in Fraser and Mach (1976), Greenler (1980), Tape (1985), and others. Research has shown that mirage images of terrestrial objects are formed when light from distant objects passes through air of varying density. Variations in density and associated variations in the refractive index of light are caused mainly by vertical temperature gradients near the earth's surface. The number of images of the object, the orientation, the sharpness, the distortion, the brightness, and other features of the mirage are largely a function of the complexity of the temperature structure. A superior mirage occurs when the air next to the surface is cooler than the air above it. Light from a distant object is refracted downward toward cooler, denser air thus producing an image of the object that is displaced above the object's true position. An inferior mirage occurs when surface air is warmer than the air above it resulting in the refraction of light upward toward cooler air thus causing the image of the object to be below the object's true position.

Recently, Tape (1985) used topological principles to show that many features of mirages can be explained without detailed knowledge of atmospheric conditions. For example, according to the odd-number theorem of the transfer-mapping technique described by Tape, a superior mirage will contain an odd number of images displaced from that object. Also, strong magnification and demagnification of multiple images of the object may occur, which according to Tape, may explain the multiple horizontal spikes observed in certain spectacular mirages such as the Fata Morgana.

\section{() 1986 American Meteorological Society}

The mirage images that we report here were observed in late autumn 1985 and in winter 1986. At dawn on 22 November 1985, we photographed a superior mirage across the Falcon Valley north of Tucson. We observed the mirage for several minutes as we traveled north on United States highway 89 from Tucson into the Falcon Valley (see Fig. 1). We

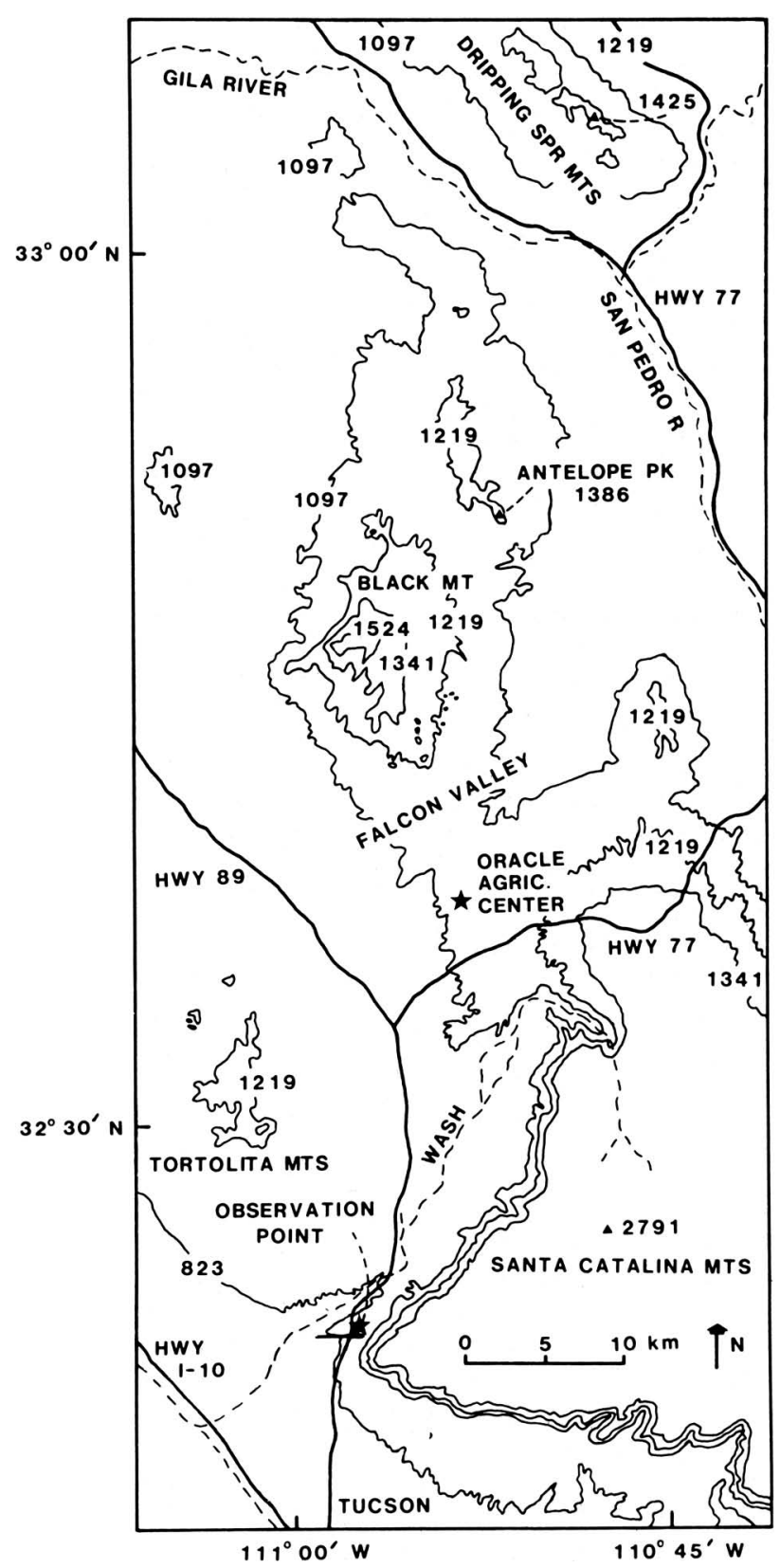

FIG. 1. Topographic map showing principal terrain features (Black Mountain, Antelope Peak, and Dripping Springs Mountains) believed to have been objects of a superior mirage north of Tucson 22 November 1985. 
stopped our vehicle at about 0715 MST (Mountain Standard Time) to photograph the mirage that we saw along the northern horizon. The observation location was at about $805 \mathrm{~m}$ above mean sea level. Our view to the north included primarily Black Mountain and its bajada. The Tortolita Mountains were to the left and the Santa Catalina Mountains were to the right. Photographs (Ektachrome ASA 200, 35-mm film) of the mirage were taken with a handheld automatic Nikon-FG camera fitted with a standard 50-mm lens. At dawn on 5 December, comparison photographs of the northern horizon with no mirage present were taken from nearly the same location.

Enlargements of representative photographs are given in Figures $2 \mathrm{a}$ and $2 \mathrm{~b}$. Figure $2 \mathrm{a}$ shows the 22 November mirage near the center along the horizon. Black Mountain is to the left. The bush in the foreground masks portions of the left edge of the mirage above the bajada. In contrast to Fig. $2 a$, Fig. $2 b$ presents the same general view with no mirage present. In Fig. 2b, we see the tops of distant mountain peaks that formed parts of the mirage near the center and to the right in Fig. 2a. These peaks are probably Antelope Peak $(53 \mathrm{~km}$ away), and possibly an unnamed peak (elevation $1425 \mathrm{~m}$ ) in the Dripping Springs Mountains $78 \mathrm{~km}$ away as illustrated in Fig. 1.

Meteorological information associated with the mirage was derived from 1) the 1500 GMT (0800 MST) NMC (National Meteorological Center) surface analysis for 22 November 1985 provided by the National Weather Service, 2)
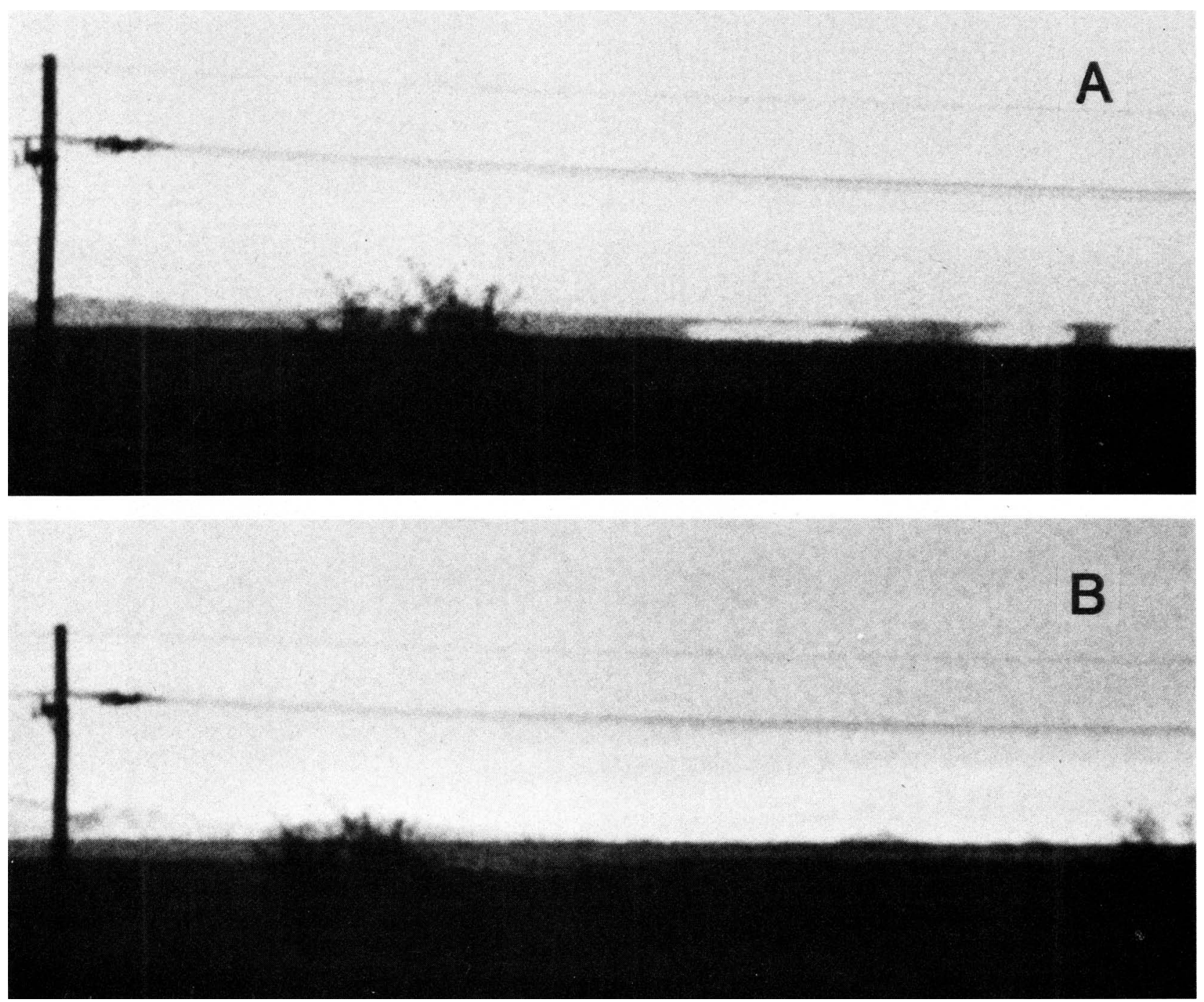

FIG. 2. (a) Photograph of superior mirage north of Tucson at about 0715 MST on 22 November 1985. Black Mountain is along left edge behind electric-power-line pole. Bush in foreground masks portions of the left edge of the mirage. The center part of the mirage is believed to be light from Antelope Peak 53-km away. Smaller part to the right may be refracted light from a peak (elevation $1425 \mathrm{~m}$ ) within the Dripping Springs Mountains $78-\mathrm{km}$ away. Horizontal field of view $\simeq 7^{\circ}$. (b) Photograph taken 5 December 1985 of nearly the same scene as in Fig. $2 \mathrm{a}$, but with no mirage present. 

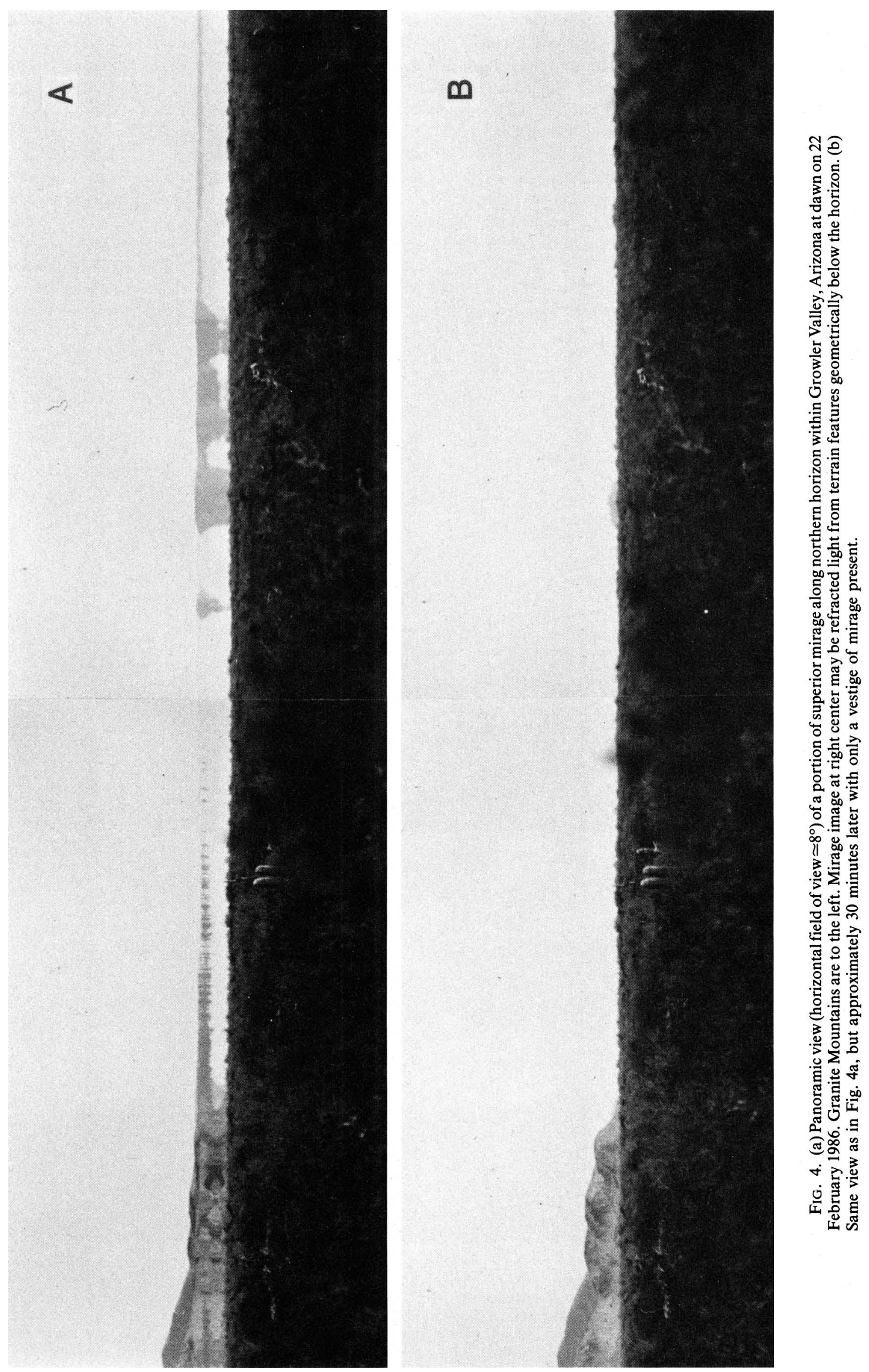


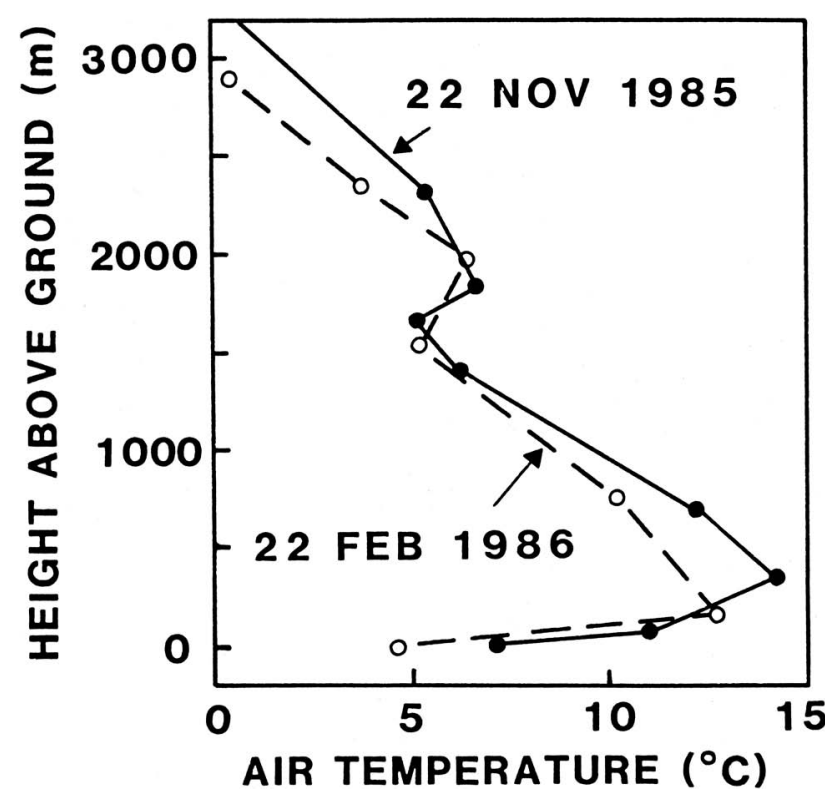

FIG. 3. The 1200 GMT National Weather Service upper-air soundings of temperature above Tucson Airport (elevation $787 \mathrm{~m}$ ) for 22 November 1985 and 22 February 1986. the 1200 GMT 22 November 1985 upper-air sounding from a radiosonde released by the National Weather Service at the Tucson International Airport, and 3) a University of Arizona remote automated weather station at the Oracle Agricultural Center in the Falcon Valley (see Fig. 1).

The 1500-GMT surface analysis contained a high pressure on the north end of the Arizona-New Mexico border. Air and dew-point temperatures at the Tucson airport were $6.1^{\circ} \mathrm{C}$ and $-3.9^{\circ} \mathrm{C}$, respectively. Winds were southerly at about $5 \mathrm{kt}$.

As shown in Fig. 3, strong temperature-inversion conditions (about $0.02^{\circ} \mathrm{C} \cdot \mathrm{m}^{-1}$ ) were observed at $1200 \mathrm{GMT}$ to a height of about $350 \mathrm{~m}$ (relative to the airport elevation of $787 \mathrm{~m}$ above sea level). Upper-air winds were generally south-southwesterly, thus the radiosonde may have passed over the general area of the mirage about one to two hours before the sighting of the mirage.

Surface conditions in the general area of the mirage were strongly influenced by local terrain effects and a lack of cloud cover, and were similar to conditions at the Tucson airport in the Tucson Valley south of the Falcon Valley. Between 0700 and $0800 \mathrm{MST}$, air temperature, relative humidity, and wind speed averaged $4.9^{\circ} \mathrm{C}, 71 \%$, and $2.8 \mathrm{~m} \cdot \mathrm{s}^{-1}$, respectively, at the Oracle Agricultural Center. The sky had been virtually cloudless the previous 24 hours, and cold-air drainage from the higher elevations during the night probably enhanced the formation of a strong temperature inversion. We believe the surface-air-temperature inversion measured above the Tuc-

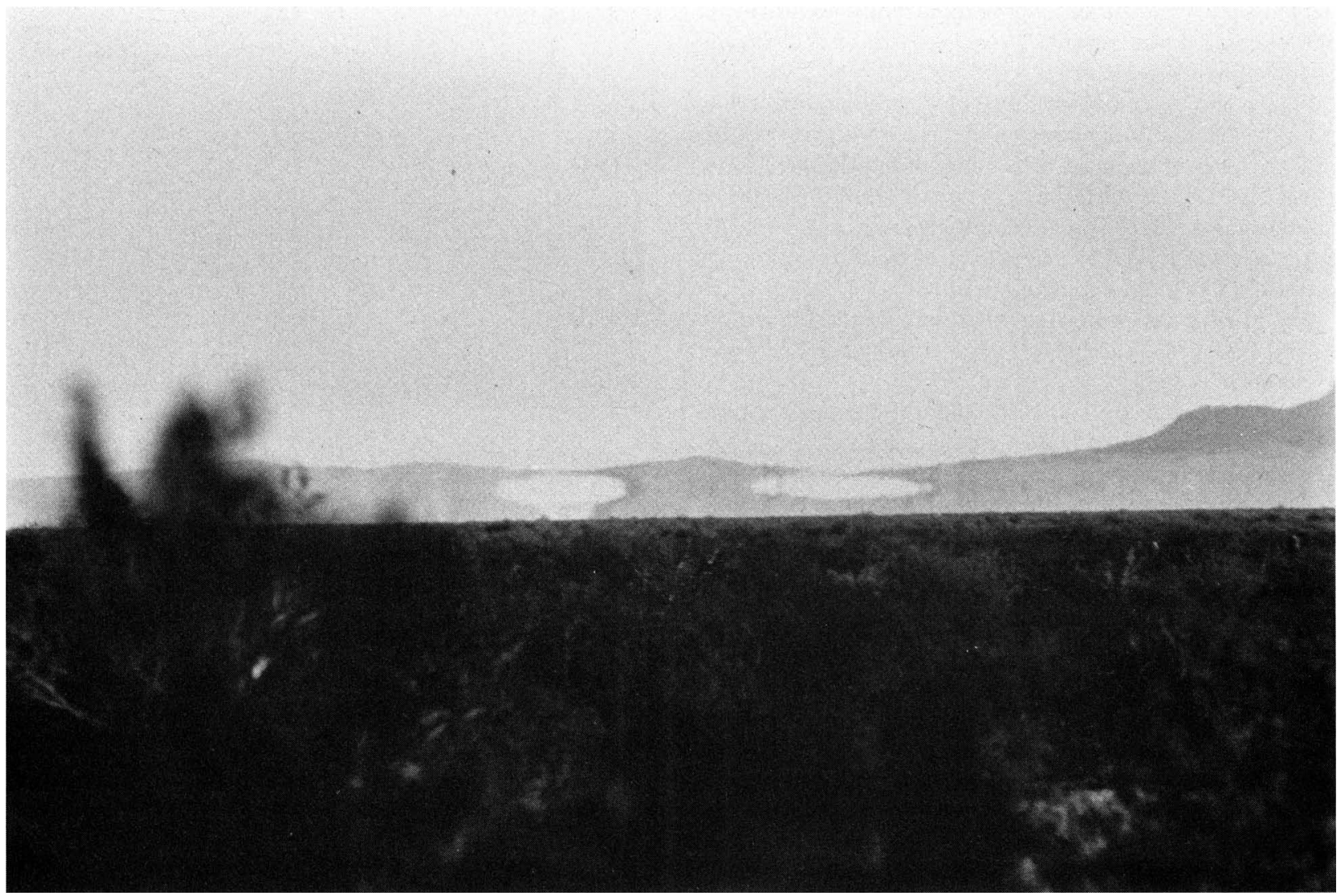

FIG. 5. Superior mirage along Growler Mountains, which form eastern boundary of Growler Valley. View presented here is nearly a continuation of the right edge of the view in Fig. 4a. Horizontal field of view $\simeq 5^{\circ}$. 
son airport (Fig. 3) may have been similar in magnitude to the inversion in the area of the mirage sighting because of similarity of terrain, and close proximity of the areas.

Since our sighting of the 22 November mirage, boundarylayer conditions have been favorable for additional superiormirage occurrences near Tucson. Particularly favorable conditions occurred at dawn on 22 February 1986. One of us (ADM) observed, with the aid of binoculars, a spectacular mirage across the Tucson Valley. Viewed from the north side of the Tucson Valley, the mirage phenomenon extended about $20^{\circ}$ along the southern horizon just west of the Santa Rita Mountains, and lasted about one hour.

The mirage on 22 February was clearly visible, and was due presumably to strong temperature-inversion conditions within the Tucson Valley. Figure 3 presents air-temperature data from the National Weather Service 1200 GMT 22 February 1986 upper-air sounding above the Tucson International Airport. It shows that the increase in air temperature with height near the surface was very similar to that for 22 November.

On that same morning (22 February) one of us (NF) was at a campsite in the Growler Valley, approximately $220 \mathrm{~km}$ west of Tucson. From that site she photographed the striking transformations that occurred in superior-mirage images observed north of the campsite. These transformations are shown in Figures 4 to 6 and are due presumably to changes occurring in the surface-layer temperature structure within that valley. These photographs (ASA 64 Kodachrome film) were taken with a Chinon camera fitted with a $400-\mathrm{mm}$ telephoto lens. All photographs were taken during a 30-minute period shortly after sunrise $(\approx 0700 \mathrm{MST})$.

Fig. 4a shows a portion of the complex mirage extending from the Granite Mountains on the left to the center of the valley. The inverted image of portions of the Granite Mountains is apparent in the figure. Portions of the mirage may be refracted light from terrain elements geometrically below the horizon, as evidenced by a later view of the terrain (Fig. 4b) with only a vestige of mirage present.

Fig. 5 shows the spectacular refraction of light that was occurring along the east edge of the valley in the Growler Mountains.

Fig. 6 presents the complex-temporal changes that occurred in the refracted light near the center of the valley. These changes occurred over a period of about 20 minutes, and may be evidence of complex transformations of temperature gradients within the boundary layer during the early morning of 22 February. Evidence of small multiple horizontal spikes due to image demagnification may be present in parts of the mirage photographs shown in Fig. 6. There may be as many as three vertically displaced demagnified images of terrain features apparent in the middle two photographs. The three images would be consistent with the odd-number theorem for superior mirages (Tape, 1985).

Sonoran Desert valleys may provide suitable locations for further field studies of mirage phenomena. Photometricmirage data in conjunction with tower or Tethersonde ${ }^{\circledR}$ data may be of use in further testing and application of recently developed inversion techniques for deducing temperature profiles in the lower atmosphere (Mach and Fraser, 1979; Lehn, 1983).
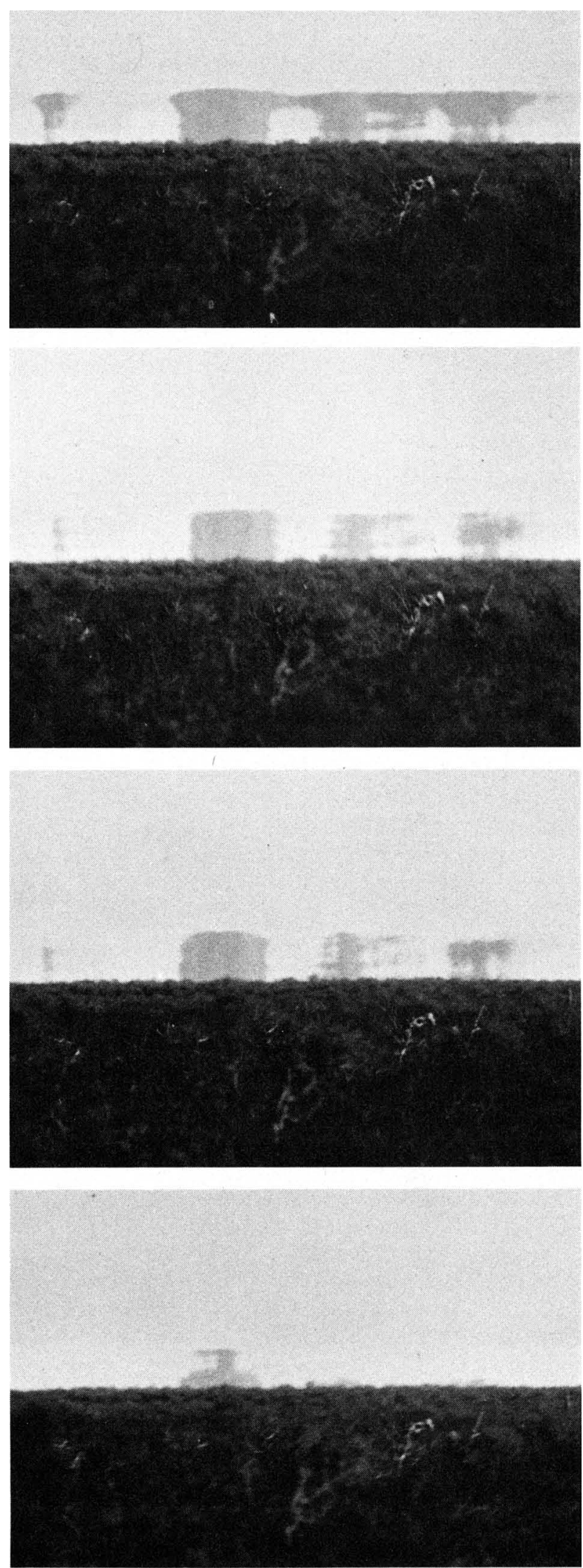

FIG. 6. Time sequence of photographs (top to bottom) showing complex-temporal changes within about a 20-minute interval in mirage within Growler Valley on 22 February 1986 . Horizontal field of view $\simeq 3^{\circ}$. 
Acknowledgements. We appreciate the help given by Dr. William Sellers, Dr. James Simpson, and Ms. Sheri Musil of the University of Arizona, and by Ms. Kitty Smith of the National Weather Service Office, Tucson. This article is published as Arizona Agricultural Experiment Station Article 4177 of the University of Arizona, Tucson, AZ.

\section{References}

Fraser, A. B., and Mach, W. H., 1976: Mirages. Sci. Amer., 234, 102-111.
Greenler, R., 1980: Rainbows, Haloes, and Glories. Cambridge University Press, Cambridge, 195 pp.

Ives, R. L., 1948: Meteorological conditions accompanying mirages in the Salt Lake Desert. J. Franklin Institute, 245, 457-473.

Lehn, W. H., 1983: Inversion of superior mirage data to compute temperature profiles. J. Opt. Soc. Am., 73, 1622-1625.

Mach, W. H., and Fraser, A. B., 1979: Inversion of optical data to obtain a micrometeorological temperature profile. Applied Optics, 18, 1715-1723.

Meinel, A., and Meinel, M., 1983: Sunsets, Twilights, and Evening Skies. Cambridge University Press, Cambridge, 163 pp.

Tape, W., 1985: The topology of mirages. Sci. Amer., 252, 120129. announcements (continued from page 1232)

of buildings to resist tornado and hurricane winds and interpretation of wind-load standards and codes. The topics to be discussed include wind-load concepts; provisions of ANSI A58.11982; design for hurricane winds; design for tornadoes; and window-glass design. A set of lecture notes, a copy of the ANSI standard, and a new commentary of ANSI wind-load provisions will be provided to each participant. For additional information and application forms, contact Martha Hise, Department of Continuing Education, Texas Tech University, P.O. Box 4110, Lubbock, TX 79409, telephone (806) 742-1522.

3 December 1986. The Starr Memorial Lecture this year will be held at the Massachusetts Institute of Technology in Room 66-110 at 2:30 in the afternoon on Wednesday, 3 December 1986. Walter H. Munk of the Institute of Geophsyics and Planetary Physics, Scripps Institution of Oceanography, University of California at San Diego will be the speaker. The title of his speech is "Ships from Space."

3-4 December 1986. The Acid Rain Information Clearinghouse will sponsor a conference titled "Acid Rain: The Relationship Between Sources and Receptors" in December.

The Acid Rain Information Clearinghouse is a project of the Center for Environmental Information, Inc., a nonprofit organization in Rochester, New York. This conference is designed for a nontechnical audience, as well as specialists in acid-rain research. The program will cover the nature and scope of scientific understanding and research programs; identify areas of consensus and disagreement; and assess policy options in the light of current understanding.

To request a program brochure, contact the Acid Rain Information Clearinghouse, 33 South Washington Street, Rochester, NY 14608, telephone (716) 546-3796.

10-12 December 1986. An international specialty conference conducted by the Air Pollution Control Association will be held at the Sheraton New Orleans Hotel and Towers, New Orleans, La. The conference will focus on such topics as thermal destruction; waste minimization/reuse; fixation/stabilization; physical, chemical, biological treatment; industry case studies; emerging/innovative technologies; and risk/cost assessment of alternative technology. For more information, contact the Meetings Department, Air Pollution Control Association, P.O. Box 2861, Pittsburgh, PA 15230; telephone (412) 232-3444.
2-6 February 1987. A short course, "Air Pollution: Simulation Modeling and Measurement Strategies," will be held in Los Angeles, California in February 1987. The four-and-one-halfday course will provide intensive training in virtually all aspects of air-pollution modeling and the measurement of model parameters. The main course lecturers will be Roger Pielke, John Seinfeld, Ivar Tombach, and Paolo Zannetti. The course fee is $\$ 750$ per participant. The course will be held in the Pasadena-Monrovia area of Los Angeles. For additional information, please contact Ms. Pat Ellis or Dr. Paolo Zannetti, AeroVironment Inc., 825 Myrtle Avenue, Monrovia, CA 910163424; telephone (818) 357-9983. Applicants are encouraged to make early reservations.

March 1987. A specialty conference on "Mobile Sources/ Emerging Issues" will be conducted by the Air Pollution Control Association in March 1987 in Windsor, Ontario. The conference will explore the latest issues associated with mobile sources and their control as the 1987 U.S. Clean Air Act deadlines approach. Topics to be discussed include an overview of mobile source-related air-quality issues; heavy-duty diesel particulates; composition of fuels; alternative fuels; in-use programs; and air-quality strategies. For more information, contact Dr. John McGovern, Member Services Manager, Air Pollution Control Association, P.O. Box 2861, Pittsburgh, PA 15230, telephone (412) 232-3444.

\section{Deadlines calendar}

Fellowships, grants, etc.

15 June $1987 \quad$ Macelwane Annual Award (this issue, p. 1284)

15 June $1987 \quad$ Hanks and Orville Scholarships (this issue, p. 1284)

Other

30 November 1986 oral or poster papers for the August 1987 workshop on debris torrents (June Bulletin, p. 695)

15 December 1986 proposals for TOPEX/POSEIDON research studies (August Bulletin, p. 1069)

13 February 1987 requests for NCAR aircraft (September BULLETIN, p. 1131)

1 March 1987 requests for NCAR field-observing support (September BULLETIN, p. 1131) 